\title{
Robótica Criativa: desenvolvimento de projetos de engenharia com crianças e jovens
}

\author{
Gabriel Sant'Clair ${ }^{1}$, Julia Godinho ${ }^{1}$, Janaína Gomide ${ }^{1}$ \\ ${ }^{1}$ Engenharias - Universidade Federal do Rio de Janeiro (UFRJ) - Campus Macaé \\ Macaé - RJ - Brasil \\ \{gsantclair, juliagodinho08, janainagomide\}@gmail.com
}

\begin{abstract}
The purpose of this article is to present an experience report for the development of engineering projects for teaching programming and robotics to children and teenagers. Also, it proposes a methodology for the classes that combine science, technology, arts and engineering for creating prototypes of engineering projects with low-cost materials. The methodology used in class is project-based learning, encouraging students to develop a central role in the course. Four projects were developed: traffic light, drawbridge, mechanical arm and smart home. A total of 71 students carried out activities in an engaged manner and more than $90 \%$ of them enjoyed the experience and want to learned more about programming.
\end{abstract}

Resumo. O objetivo desse artigo é apresentar um relato de experiência sobre o desenvolvimento de projetos de Engenharia para o ensino de programação $e$ robótica com crianças e jovens. Além disso, esse artigo propõe uma metodologia para as aulas que associa Ciência, Tecnologia, Artes e Engenharia para a confecção de protótipos dos projetos com materiais de baixo custo. Foram desenvolvidos quatro projetos: semáforo, ponte levadiça, braço mecânico e casa inteligente. Um total de 71 crianças e jovens participaram das atividades de forma engajada e mais de $90 \%$ deles disseram gostar da experiência realizada e desejam aprender mais sobre programação.

\section{Introdução}

O ensino da programação de computadores para crianças vem sendo estimulado no Brasil e diversas iniciativas têm surgido visando o seu desenvolvimento desde a educação básica, [França and Tedesco 2019].

Alguns relatos de experiência, como em [Souza and Castro 2016, Carlos et al. 2018], mostraram sucesso ao utilizarem ferramentas online próprias para crianças e jovens. Essas ferramentas utilizam linguagem em blocos (clica e arrasta os comandos) e algumas incluem a linguagem escrita, [Cafiero et al. 2018].

Outra abordagem adotada no ensino da programação é a robótica educacional, que visa motivar e engajar os alunos, [Komm et al. 2020]. A construção de robôs envolve dispositivos, sensores e circuitos eletrônicos e utiliza, por exemplo, a placa Arduino para a criação de um projeto. Em [Cunha and Nascimento 2019] os autores relatam a experiência de um projeto desenvolvido com alunos do Ensino Fundamental, cujo foco foi o pensamento computacional por meio do ensino de programação e robótica. Iniciativas apresentadas nos trabalhos [Braga et al. 2018] e [Santos et al. 2010] destacam que a 
elaboração de tecnologias de baixo custo para o ambiente ensino-aprendizado permite que essas sejam acessíveis a instituições educativas com poucos recursos econômicos.

Esse artigo expõe uma proposta de minicursos e oficinas para o ensino de programação para crianças e jovens, associando Ciência, Tecnologia, Artes e Engenharia. A temática das aulas é projetos de Engenharia, que são desenvolvidos com diferentes enfoques para crianças e jovens. Ao apresentar os temas de Engenharia para crianças, essas são estimuladas a pensarem e descreverem o funcionamento do protótipo utilizando a criatividade. Para os jovens, os projetos de Engenharia são contextualizados dentro dos cursos de graduação, divulgando possíveis carreiras e profissões. Os projetos são confeccionados utilizando kits de robótica desenvolvidos pela equipe, com custo aproximado de $\mathrm{R} \$ 80$ a $\mathrm{R} \$ 110$, e materiais de baixo custo, como papelão, cartolina, palito de picolé, dentre outros.

A metodologia de ensino utilizada nas aulas é Aprendizado por Projeto, prática na qual o professor possui um papel menos central, apenas assessorando os alunos e os incentivando a participarem ativamente do processo de investigação, [Marques et al. 2014]. A dinâmica dos minicursos e oficinas é composta por seis fases e se inicia com a apresentação do projeto de engenharia que será desenvolvido, seguido da elaboração do algoritmo que descreve o seu funcionamento. Os participantes aprendem sobre circuitos eletrônicos e criam a maquete do projeto com materiais de baixo custo. A placa Arduino é utilizada na fase da robótica e, a última fase, consolida as anteriores finalizando o protótipo do projeto de Engenharia.

O objetivo desse artigo é apresentar um relato de experiência para o desenvolvimento de projetos de Engenharia no ensino de programação e robótica com crianças e jovens. A experiência relatada nesse trabalho pode ser utilizada como material de apoio a projetos e escolas que queiram reproduzir este método. As próximas seções descrevem, em detalhe, a metodologia de ensino, os projetos de Engenharia propostos, os resultados alcançados e a conclusão.

\section{Metodologia}

A metodologia utilizada, baseada em Aprendizado por Projeto, é composta por seis fases: (1) Ideia do Projeto; (2) Programação; (3) Eletrônica; (4) Maquete; (5) Robótica; e (6) Consolidação. Cada fase tem como resultado a construção de um conhecimento específico ou a entrega de uma parte necessária do produto final. Em cada nova fase os monitores recordam os conhecimentos desenvolvidos nas fases anteriores.

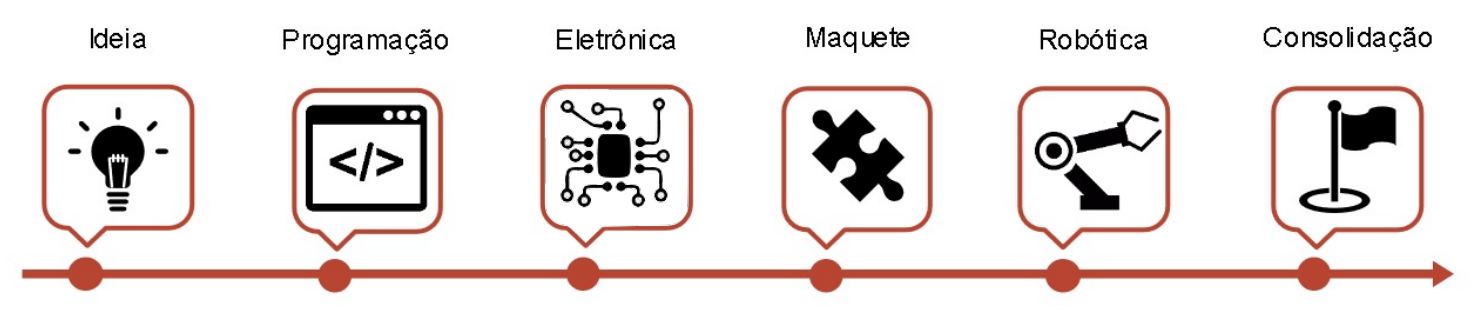

Figura 1. Fases do projeto

Na primeira fase, Ideia do Projeto, o projeto de engenharia é apresentado visando despertar o interesse e a curiosidade dos alunos ao questioná-los sobre o seu funciona- 
mento. Além disso, discute-se sobre a presença da Engenharia no cotidiano e sobre a atuação do profissional na área.

Na segunda fase, Programação, os monitores orientam a turma a criar um passo a passo descrevendo o funcionamento do projeto. Os alunos escrevem o algoritmo do projeto e são introduzidos aos conceitos básicos de programação: comandos condicionais, comandos de repetição, operadores Booleanos e variáveis. O algoritmo é implementado utilizando o software $\operatorname{Scratch}^{1}$, como mostra o exemplo da Figura 2a.

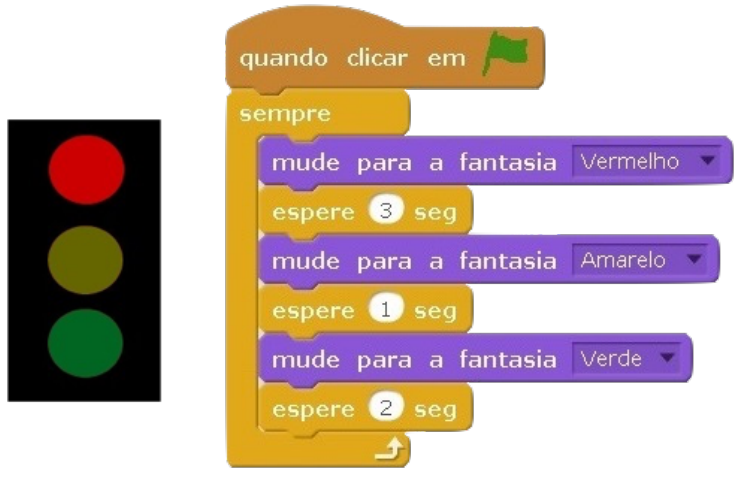

(a)

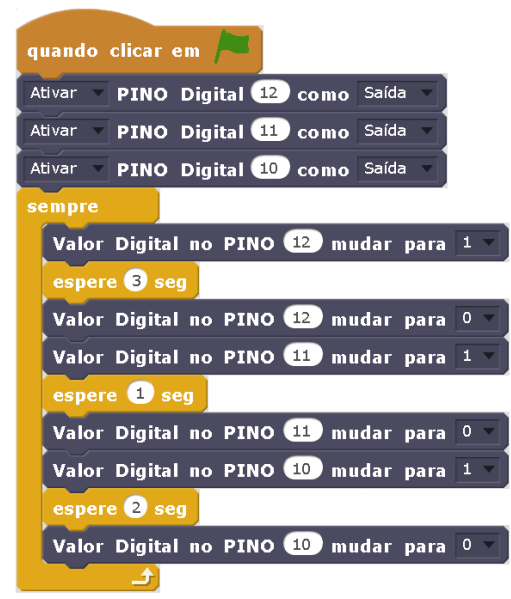

(b)

Figura 2. Projeto do Semáforo: (a) Programação: código criado no Scratch, (b) Robótica: código criado utilizando blocos para robótica.

Na terceira fase, Eletrônica, os alunos aprendem sobre circuitos eletrônicos e seus componentes. A massa de modelar é utilizada como condutor elétrico a fim de facilitar o entendimento, Figura 3a. São montados circuitos eletrônicos básicos, como circuitos em série e em paralelo. Posteriormente, são desenvolvidos os mesmos circuitos com auxílio da protoboard, placa utilizada na montagem de circuitos experimentais, Figura 3b. Os circuitos eletrônicos elaborados nessa fase não possuem relação direta com o projeto a ser desenvolvido, o objetivo é apresentar conceitos básicos de circuitos eletrônicos.

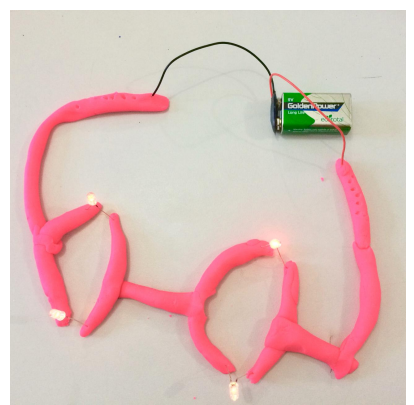

(a)

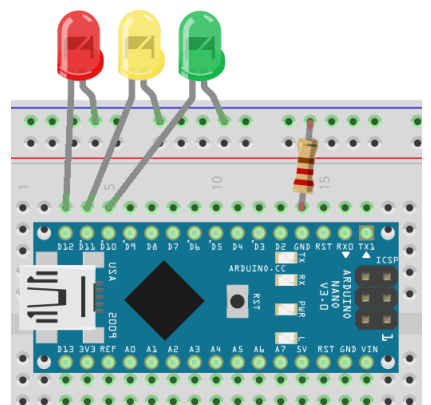

(b)

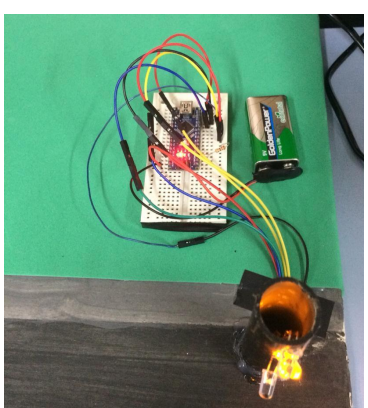

(c)

Figura 3. Circuito Eletrônico: (a) utilizando massa de modelar, (b) montado na protoboard, (c) incorporado na maquete.

\footnotetext{
${ }^{1}$ Scratch: https://scratch.mit.edu/
} 
Os alunos são motivados a usarem a criatividade na montagem da Maquete do projeto, quarta fase. Utilizam-se materiais de baixo custo como papelão, cartolina, palitos e canos, Figura 3c. Os participantes escolhem os materiais com que irão construir o projeto.

Na quinta fase, Robótica, apresenta-se a placa Arduino explicando seu funcionamento e os conceitos de eletrônica digital. Os alunos montam novos circuitos eletrônicos de acordo com as especificações do projeto. O Scratch é utilizado para a comunicação entre o computador e a placa Arduino com o auxílio de blocos extras obtidos pelo software HackEduca Conecta ${ }^{2}$, Figura 4. É necessário ativar as portas que serão utilizadas de acordo com o componente eletrônico: Entrada, Saída, Servo ou Ultrassom. A porta Entrada recebe informação digital ou analógica, a porta Saída emite sinal digital, a Servo se comunica com um servomotor e a porta configurada como Ultrassom recebe informação de um sensor ultrassônico, geralmente associada a distância entre o sensor e um objeto. Por fim, são feitas adaptações no algoritmo desenvolvido na fase Programação utilizando os blocos extras da robótica, Figura $2 b$.
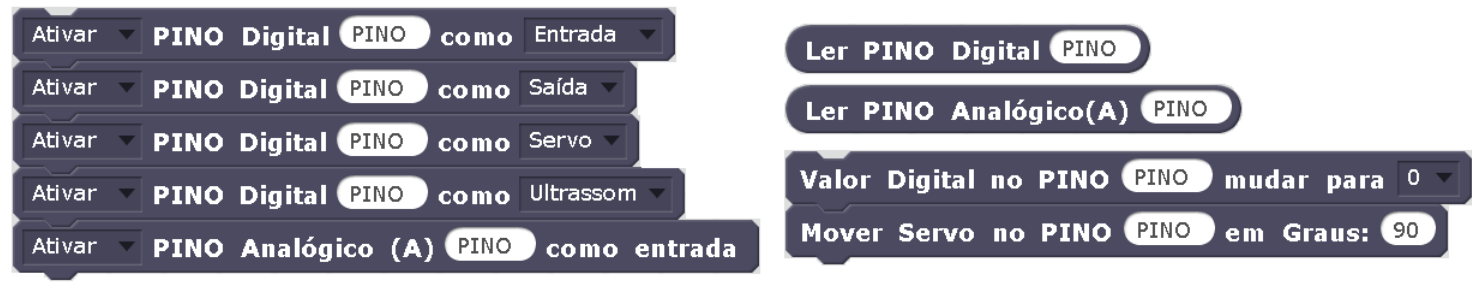

Figura 4. Blocos extras para comunicação entre o Scratch e a placa Arduino.

Na última fase, Consolidação, o projeto é colocado em funcionamento combinando os resultados das fases anteriores: a programação, o circuito eletrônico e a maquete. Relembram-se os conceitos aprendidos ao longo das fases anteriores. Espera-se que os participantes concluam que foram capazes de refletir, esquematizar e reproduzir o funcionamento de um projeto de engenharia presente no dia a dia.

\section{Resultados}

Nesta seção são apresentados os projetos de Engenharia criados para ensino de programação e as cursos realizados.

\subsection{Projetos de Engenharia}

Foram criados quatro projetos de Engenharia, Tabela 1. Os projetos contemplam áreas da Engenharia Civil e Engenharia Mecânica e suas etapas abrangem conceitos básicos de programação.

O projeto do Semáforo de trânsito, Figura 3b, é composto de luzes coloridas (vermelho, amarelo e verde) que acendem em sequência. Os monitores iniciam a atividade conversando com os alunos sobre a Engenharia Civil e qual o seu papel no planejamento de cidades. A programação se baseia em uma estrutura de repetição simples com comandos temporizadores, Figura 2b. A parte eletrônica é composta por três LEDs de cores distintas e um resistor. São necessárias três portas digitais do Arduino para os comandos

\footnotetext{
${ }^{2}$ HackEduca Conecta: https: //www. hackeduca.com.br/
} 
de acender e apagar os LEDs. A maquete pode ser constituída de cano PVC com furos para os LEDs coloridos.

Tabela 1. Projetos desenvolvidos.

\begin{tabular}{ll}
\hline Projeto 1: Semáforo \\
\hline Ideia do Projeto & Luzes de um semáforo \\
Programação & Comandos de repetiçãp \\
Eletrônica & 3 LEDs, 1 Resistor, 1 Breadboard, 1 Arduino Nano \\
Maquete & Isopor, cartolina e tinta \\
Custo & R $\$ 80,00$ \\
Projeto 2: Ponte Levadiça \\
\hline Ideia do Projeto & Ponte basculante \\
Programação & Comandos de repetição, variáveis e comandos condicionais \\
Eletrônica & 2 Micro servo motores, 1 protoboard, 1 Arduino Nano \\
Maquete & Palitos de picolé e tinta \\
Custo & R $\$ 110,00$ \\
Projeto 3: Braço Mecânico \\
\hline Ideia do Projeto & Braço mecânico com duas articulações \\
Programação & Comandos de repetição, variáveis e comandos condicionais \\
Eletrônica & 2 Micro servo motores, 1 protoboard, 1 Arduino Nano \\
Maquete & Cano de PCV e fita isolante \\
Custo & R $\$ 110,00$ \\
Projeto 4: Casa Inteligente \\
\hline Ideia do Projeto & Acionamento automático de luzes por luminosidade \\
Programação & Comandos de repetição, variáveis e comandos condicionais \\
Eletrônica & 1 LED, 1 LDR, 2 resistores, 1 protoboard, 1 Arduino Nano \\
Maquete & Isopor, cartolina e tinta \\
Custo & R $\$ 80,00$ \\
\end{tabular}

No projeto da Ponte Levadiça, Figura 5, o objetivo é construir uma ponte dividida em duas partes. Os monitores discutem com os alunos sobre o funcionamento desta estrutura e os esforços que as pontes devem aguentar, conceitos de cálculo estrutural. A programação se baseia em estruturas de repetição incluídas dentro de estruturas condicionais para garantir um movimento gradual e lento das partes móveis. A parte eletrônica é composta por dois servomotores, sendo necessárias duas portas digitais do Arduino, uma para cada servomotor, e a porta $5 \mathrm{~V}$, para alimentação dos servomotores. A maquete pode ser constituída de palitos de picolé colados, formando uma base para o servomotor e uma parte movente. Deve-se atentar para o posicionamento dos servomotores na estrutura a fim de garantir o movimento esperado com o acionamento dos botões.

O projeto da Casa Inteligente, Figura 6, compreende o acionamento automático de luzes com o uso de fotorresistores (LDRs). No desenvolvimento do projeto os monitores discutem com os alunos o papel da Engenharia em buscar soluções com menor impacto ambiental e mais econômicas. A programação usa uma estrutura condicional que recebe informação analógica do LDR e um valor limite de leitura para determinar o acionamento do LED. A parte eletrônica é composta por um LED, um LDR e dois resistores. São 


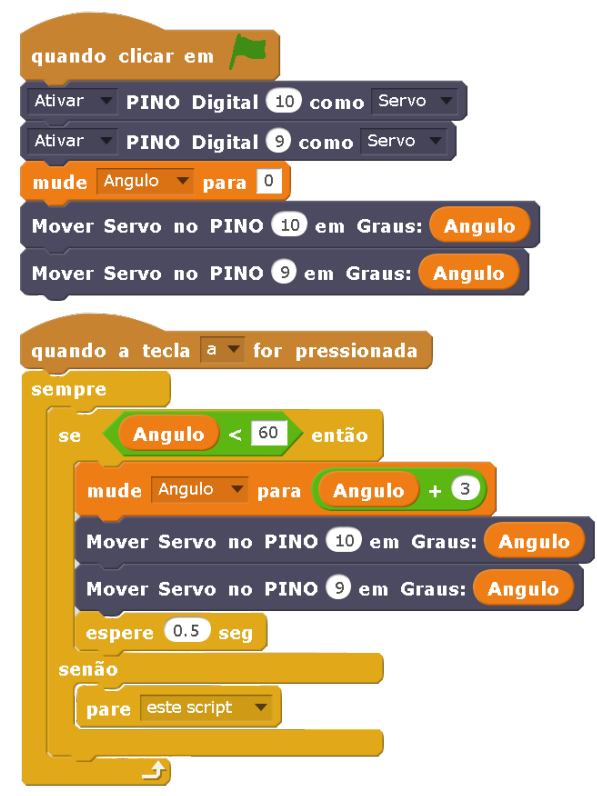

(a)

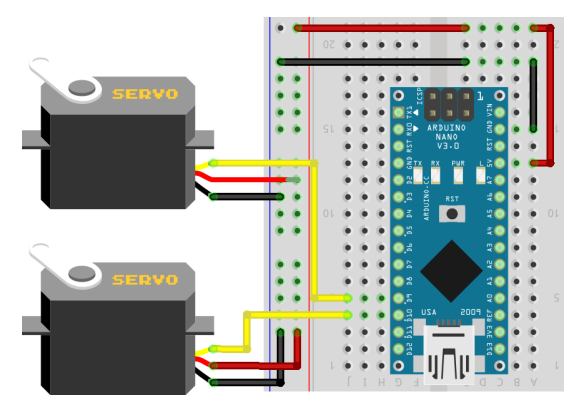

(b)

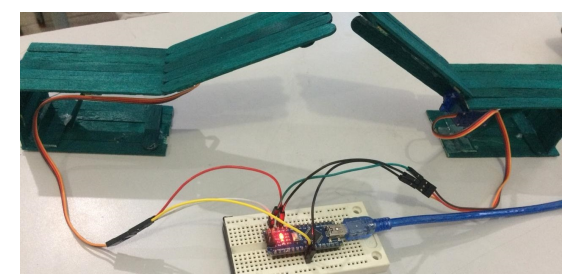

(c)

Figura 5. Ponte Levadiça: (a) Algoritmo, (b) Circuito, (c) Maquete

necessárias uma porta digital e uma porta analógica do Arduino e, para a alimentação do LDR, utiliza-se a porta $5 \mathrm{~V}$. A maquete simula uma casa com o LDR na parte exterior para que haja controle de luminosidade e com o LED na parte interior.

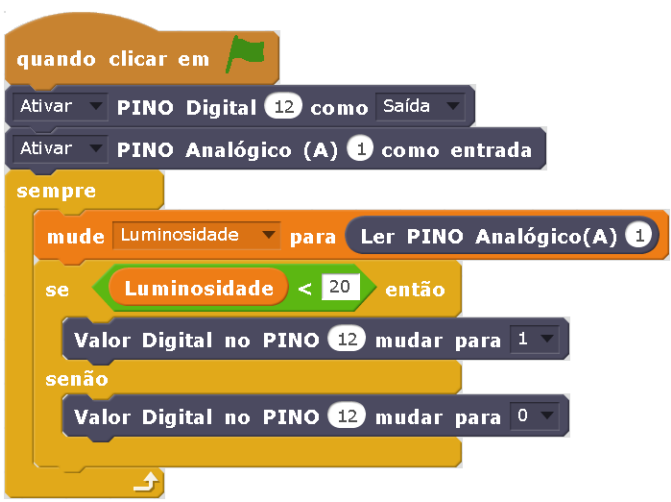

(a)

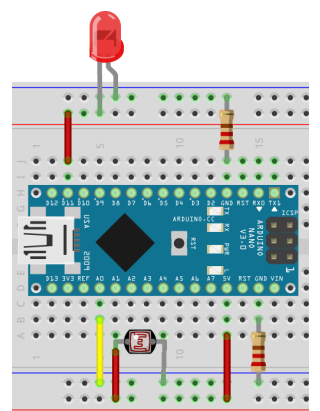

(b)

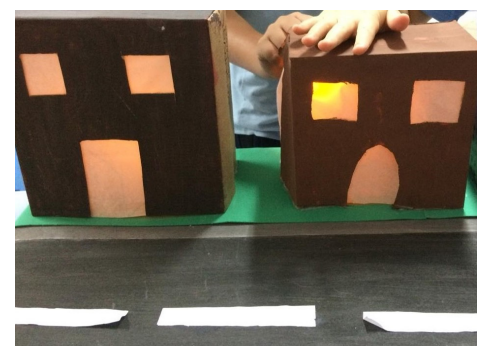

(c)

Figura 6. Casa Inteligente: (a) Algoritmo (b) Circuito (c) Maquete

O projeto do Braço Mecânico, Figura 7, é composto por um mecanismo dividido em duas partes moventes, com funcionamento parecido a uma retroescavadeira. No desenvolvimento do projeto os monitores discutem com os alunos qual será o movimento da estrutura ao acionar os servomotores, conceitos de dinâmica dos corpos rígidos. A programação se baseia em estruturas condicionais, que serão acionadas por botões do computador, possibilitando que o servomotor rotacione uma angulação específica, transmitindo o movimento angular a toda estrutura. A parte eletrônica consiste de dois servomotores, sendo necessárias duas portas digitais do Arduino, uma para cada servomotor, e a porta $5 \mathrm{~V}$ para alimentação dos servomotores. O circuito da Ponte Levadiça é idêntico ao circuito do Braço Mecânico, Figura 5b. A maquete pode ser constituída de canos PVC, 
serrados ao meio, ligados a cada servomotor, sendo necessária uma base de apoio para o primeiro servomotor.

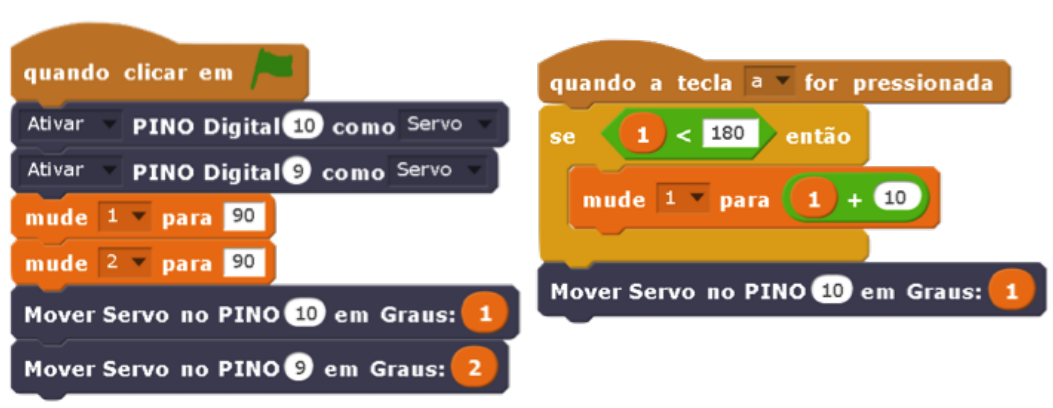

(a)

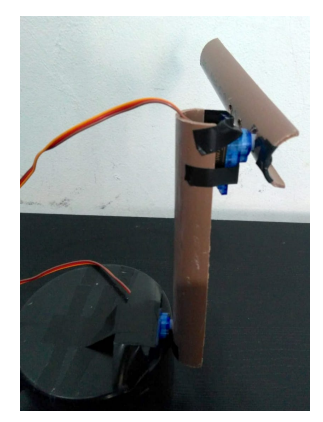

(b)

Figura 7. Braço Mecânico: (a) Algoritmo (b) Maquete

\subsection{Minicursos e Oficinas}

Foram criados minicursos e oficinas para o ensino de programação e robótica utilizando os projetos de Engenharia. Os minicursos foram oferecidos em duas escolas de Ensino Fundamental. A carga horária de cada minicurso foi de oito a dez horas, divida em encontros semanais de duas horas. As oficinas possuíram carga horária de quatro horas dividas em dois encontros. A realização das oficinas aconteceram em parceria com dois projetos de extensão da Universidade Federal do Rio de Janeiro (UFRJ) - Campus Macaé, o projeto Aprenda a Programar Jogando ${ }^{3}$ e o projeto Ampliando os olhares na região Norte Fluminense para o relevante papel das mulheres em Ciências Exatas, da Computação e Engenharia ${ }^{4}$.

As aulas foram ministradas por graduandos da Engenharia da UFRJ - Campus Macaé e em todas as aulas havia a presença de dois monitores. No total, 71 alunos sem conhecimento prévio em computação, entre 9 e 17 anos de idade, participaram das atividades. A Tabela 2 mostra todas as turmas realizadas e a faixa etária dos alunos.

Ao iniciar as atividades, as crianças se dividiam em grupos de 2 a 4 integrantes para trabalharem em equipe. Após a orientação inicial, cada grupo iniciava suas atividades com auxílio dos monitores de acordo com as demandas. Observou-se que em turmas menores, com 5 a 9 integrantes, os monitores conseguiram realizar um acompanhamento mais próximo e atender melhor às necessidades e às dificuldades de cada aluno.

Referente à duração dos minicursos, os monitores relataram que cinco encontros de duas horas é o suficiente para que uma turma elabore um projeto seguindo todas as fases previstas na metodologia. Em relação às oficinas, que tiveram quatro horas de duração, esse formato oferece benefícios para escolas ou projetos que possuem limitação de tempo, ou para a realização em eventos. Contudo, para o aprofundamento dos temas de programação e eletrônica são necessárias mais aulas.

A diferença de carga horária entre os minicursos e as oficinas afetou a execução de algumas etapas da metodologia apresentada. Por exemplo, os alunos das oficinas não

\footnotetext{
${ }^{3}$ Projeto Aprenda a Programar Jogando, [Godinho et al. 2017] - Instagram: @ projetoaprendaprogramar

${ }^{4}$ Projeto Mulheres em Cências Exatas, da Computação e Engenharia - Instagram: @ garotascientistas
} 
IX Congresso Brasileiro de Informática na Educação (CBIE 2020)

Anais do XXVI Workshop de Informática na Escola (WIE 2020)

Tabela 2. Oficinas e minicursos realizados.

\begin{tabular}{lcccc}
\hline & Modalidade & Projetos & Faixa etária & Quantidade \\
\hline Turma 1 & Oficina & Ponte levadiça & 11 a 17 & 5 alunos e 2 grupos \\
Turma 2 & Oficina & Braço mecânico & 12 a 17 & 6 alunos e 2 grupos \\
Turma 3 & Minicurso & Semáforo & 9 a 10 & 11 alunos e 3 grupos \\
Turma 4 & Minicurso & Semáforo & 9 a 10 & 13 alunos e 4 grupos \\
Turma 5 & Minicurso & Casa inteligente & 9 a 10 & 9 alunos e 3 grupos \\
Turma 6 & Minicurso & Ponte levadiça & 9 a 10 & 14 alunos e 4 grupos \\
Turma 7 & Minicurso & Semáforo e braço mecânico & 9 a 10 & 6 alunos e 2 grupos \\
Turma 8 & Minicurso & Semáforo e ponte levadiça & 10 a 11 & 7 alunos e 2 grupos \\
\hline
\end{tabular}

puderam montar suas próprias maquetes, que foram disponibilizadas prontas pelos monitores. Portanto, as atividades foram focadas na elaboração da lógica de programação, circuito eletrônico e robótica.

Observou-se que a metodologia atendeu às expectativas dos monitores para todas as turmas, inclusive para as turmas de alunos mais novos. Cada fase foi discutida com os estudantes e, ao longo do desenvolvimento do projeto, notava-se que os alunos compreendiam quais eram os componentes necessários na elaboração de um projeto de robótica. Na primeira fase foi possível conversar sobre a atuação profissional do engenheiro e falar sobre a presença da Engenharia no cotidiano. Na segunda fase, a turma foi apresentada a conceitos básicos de programação com auxílio do Scratch. A escolha da programação em blocos foi vantajosa, uma vez que facilitou o aprendizado principalmente para as crianças. Na fase de eletrônica, observou-se que o uso de massa de modelar gerou um engajamento das crianças e auxiliou na compreensão do funcionamento dos circuitos eletrônicos. A produção da maquete foi importante para a motivação dos alunos e possibilitou que eles expressassem sua criatividade, além de estimular o trabalho em equipe. Na fase da robótica, os alunos puderam visualizar o funcionamento das estruturas de programação na resposta dos componentes do circuito.

A avaliação do aprendizado dos alunos foi realizada por meio de um questionário, que foi respondido no encerramento dos minicursos e oficinas, e pela observação dos monitores ao longo das atividades. O questionário contemplava perguntas abrangendo conhecimentos de programação, eletrônica e robótica. Quanto aos conceitos de programação, as respostas eram em texto livre e cerca de $76 \%$ dos alunos definiram corretamente o que era programação e responderam corretamente sobre o uso do conceito de comandos condicionais. Referente aos conceitos de eletrônica e robótica, foi solicitado que o participante relacionasse o conceito teórico descrito com o componente eletrônico equivalente. Mais de 74\% dos participantes responderam corretamente sobre: servo motor, protoboard, LED, Arduino e resistor. A avaliação do aluno também foi feita de forma contínua a partir da observação dos monitores, os quais notaram que os alunos obtinham melhores 
desempenhos na construção dos códigos quando trabalhavam em equipe e quando eles já haviam discutido o algoritmo anteriormente.

Concluiu-se que o uso de projetos de Engenharia foi essencial para o engajamento dos alunos, visto que mais de 95\% relataram "gostar" ou "gostar muito" da experiência ao responderem o questionário. Ao final do curso, aproximadamente $90 \%$ das crianças e jovens afirmaram querer aprender mais sobre programação e Engenharia, sendo esse um dos objetivos desse trabalho.

O questionário aplicado aos alunos das turmas 6,7 e 8 foi modificado para contemplar mais perguntas. A fim de verificar a percepção dos alunos sobre o quanto haviam aprendido, foi perguntado: "Você acredita que aprendeu sobre programação e robótica?" em uma escala de 0 à 5, sendo 0 para "não aprendi nada" e 5 para "aprendi tudo". A média das respostas foi 4 , indicando que o conteúdo foi satisfatório. Além disso, os alunos puderam opinar sobre "construção de circuitos", "programação", "dinâmica das aulas" e "explicação dos monitores". A aprovação para cada item foi superior a 90\%, que relataram "gostar" ou "gostar muito". Alguns alunos das oficinas relataram que gostariam de mais aulas.

Ao final dessa experiência, concluiu-se que alguns pontos podem ser aprimorados. Planeja-se reestruturar o questionário e aplicá-lo de forma padronizada nas turmas futuras. Espera-se, com isso, melhorar a qualidade dos dados para posterior análise de cada fase da metodologia e do aprendizado nos temas de programação e robótica. A execução da primeira fase, Ideia do Projeto, também pode ser aprimorada, abordando mais detalhes de projetos reais de Engenharia e como ocorre a atuação dos profissionais na área por meio de vídeos e imagens.

\section{Conclusão}

Esse artigo apresenta um relato de experiência sobre o desenvolvimento de projetos de Engenharia para o ensino de programação e robótica com crianças e jovens. Foram realizados minicursos e oficinas, e um total de 71 alunos entre 9 e 17 anos participaram das atividades.

O tema das aulas envolveu a criação de projetos de Engenharia Civil e Mecânica, visando motivar a curiosidade das crianças e apresentar uma possível profissão e carreira para os jovens. Foram propostos quatro projetos: semáforo, ponte levadiça, braço mecânico e casa inteligente. Para executá-los foram utilizados materiais de baixo custo, permitindo que essa experiência seja acessível para instituições e projetos com restrições em recursos econômicos.

A metodologia proposta para realização das atividades possui seis fases e envolve a apresentação dos projetos, a programação de computadores, circuitos eletrônicos e robótica e a montagem de uma maquete com materiais de baixo custo. Durante as aulas os alunos foram organizados em grupos de dois a quatro integrantes para trabalharem em equipe. Os monitores auxiliavam os alunos de acordo com suas demandas, deixando que eles tivessem autonomia na realização das atividades. Essa metodologia foi bem avaliada tanto pelos alunos quanto pelos monitores.

Observou-se que o aprendizado baseado em projetos contribuiu para formação dos alunos que tiveram papel ativo nas atividades. Na avaliação feita pelos alunos, mais 
de $95 \%$ relataram gostar da experiência e aproximadamente 90\%, aprender mais sobre programação e Engenharia. Sobre a avaliação do aprendizado, aproximadamente $74 \%$ dos alunos responderam de forma correta questões sobre programação e robótica.

Esse trabalho pode ser usado como material de apoio por outros grupos para reprodução das atividades. Dentre os trabalhos futuros, pretende-se criar novos projetos e desenvolvê-los com turmas de faixas etárias diferentes. Além disso, o questionário aplicado ao final das atividades pode ser reestruturado para acrescentar novas perguntas, visando melhorar a forma de avaliação do aprendizado dos alunos.

\section{Referências}

Braga, L. V., Braga, D. V., Gusmão, A., Souza, C., and Gualberto-Leite, N. (2018). Programchildren: Levando tecnologia para crianças de uma escola pública. In Anais do Workshop de Informática na Escola, volume 24, page 295.

Cafiero, C., Pinheiro, J. V., and Gomide, J. (2018). Avaliação das ferramentas utilizadas em um curso de programação para crianças: Percepções dos alunos e seus instrutores. In Anais do Workshop de Informática na Escola, volume 24, page 51.

Carlos, L., Godinho, J., and Gomide, J. (2018). Um relato de experiência da escola de verão de programação para crianças. In Anais do Workshop de Informática na Escola, volume 24 , page 41 .

Cunha, F. and Nascimento, C. (2019). Uma abordagem baseada em robótica para ensinar fundamentos da computação na educação básica. Anais do Workshop de Informática na Escola, 25(1):735.

França, R. and Tedesco, P. (2019). Pensamento computacional: Panorama dos grupos de pesquisa no brasil. Simpósio Brasileiro de Informática na Educação (SBIE), 30(1):409.

Godinho, J., Torres, K., Batista, G., Andrade, E., and Gomide, J. (2017). Projeto aprenda a programar jogando: Divulgando a programação de computadores para crianças e jovens. In Anais do XXV Workshop sobre Educação em Computação (WEI).

Komm, D., Regez, A., Hauser, U., Gassner, M., Lütscher, P., Puchegger, R., and Kohn, T. (2020). Problem solving and creativity: Complementing programming education with robotics. In Proceedings of the 2020 ACM Conference on Innovation and Technology in Computer Science Education, pages 259-265.

Marques, M. R., Quispe, A., and Ochoa, S. F. (2014). A systematic mapping study on practical approaches to teaching software engineering. In Proceedings of IEEE Frontiers in Education Conference (FIE), pages 1-8. IEEE.

Santos, F. L., Nascimento, F. M. S., and Bezerra, R. M. (2010). Reduc: A robótica educacional como abordagem de baixo custo para o ensino de computação em cursos técnicos e tecnológicos. In Anais do Workshop de Informática na Escola, volume 1.

Souza, S. and Castro, T. (2016). Investigação em programação com scratch para crianças: uma revisão sistemática da literatura. In Anais dos Workshops do V Congresso Brasileiro de Informática na Educação (CBIE), volume 5, page 1078. 